\title{
Out-of-pocket Spending on Orphan Drug Prescriptions Among Commercially Insured Adults in 2014
}

\author{
Kao-Ping Chua, MD, PhD and Rena M. Conti, $P h D^{2,3}$ \\ 'Department of Pediatrics and Communicable Diseases, Child Health Evaluation and Research Center, University of Michigan Medical School, \\ Ann Arbor, MI, USA; ${ }^{2}$ Department of Markets, Public Policy, and Law, Boston University Questrom School of Business, Boston, MA, USA; ${ }^{3}$ Institute for \\ Health System Innovation and Policy, Boston University Questrom School of Business, Boston, MA, USA.
}

$\mathrm{J}$ Gen Intern Med 34(3):338-40

DOI: $10.1007 / \mathrm{s} 11606-018-4694-1$

(c) Society of General Internal Medicine 2018

\section{INTRODUCTION}

Orphan drugs are products with at least one Food and Drug Administration (FDA)-approved indication to treat rare diseases affecting fewer than 200,000 Americans. Many orphan drugs also have FDA-approved non-orphan indications. ${ }^{1}$

Manufacturers of orphan drugs enjoy extended periods free from generic competition, ${ }^{1}$ allowing them considerable latitude on pricing. In 2016, annual list price spending per patient exceeded $\$ 50,000$ for $40.9 \%$ of orphan drugs, ${ }^{1}$ prompting concerns over the burden of high prices on payers. Commercially insured patients, however, may also be burdened by these prices, particularly if they pay a percentage of drug prices through deductibles and co-insurance. ${ }^{2}$ Though prior studies have examined orphan drug benefit design, ${ }^{3}$ none have examined out-of-pocket spending for these drugs. We estimated out-of-pocket spending on orphan drug prescription fills at retail and mail-order pharmacies among a national sample of commercially insured adults.

\section{METHODS}

We analyzed the 2014 Truven MarketScan Commercial Claims and Encounters database, which includes claims from non-elderly individuals who received insurance from large employers in all 50 states. ${ }^{4}$ The sample included adults aged 18-64 years with pharmacy benefit coverage who were continuously insured during 2014.

Using the FDA orphan drug database, ${ }^{5}$ we identified 119 drugs approved by the FDA to be marketed as an orphan drug by January 1, 2014, and that maintained market exclusivity during the entirety of 2014. We used national drug codes associated with the brand names of these drugs to identify prescription drug fills. We included fills whether they were for orphan or non-orphan indications.

We calculated total fills, total annual and out-of-pocket spending (the sum of deductibles, co-insurance, and co-pays), mean and median total and out-of-pocket spending per fill, mean annual total and out-of-pocket spending per orphan drug

Published online October 15, 2018 "user" (i.e., patients with $\geq 1$ fill in 2014), the percentage of users with different levels of annual out-of-pocket spending (e.g., \$0-\$100), and mean and median annual out-of-pocket spending among users who were and were not enrolled in highdeductible health plans throughout 2014. We identified the 10 drugs accounting for the most out-of-pocket spending.

\section{RESULTS}

Among our sample of 19,182,738 adults, there were 200,207 orphan drug users (1.0\% of the sample) (Table 1). These users filled 744,182 orphan drug prescriptions in 2014.

Total annual spending on orphan drugs was $\$ 2.2$ billion, mean total spending per fill was \$2902 (median \$1614), and mean annual total spending per user was $\$ 10,786$ (median \$727). Total annual out-of-pocket spending represented $3.1 \%$ of total annual spending.

Mean out-of-pocket spending per fill was \$90 (median \$40) and mean annual out-of-pocket spending per user was $\$ 333$ (median \$96). Among all users, 52.6\% spent \$0-\$100 per year out-of-pocket, $14.4 \%$ spent more than $\$ 500$, and $0.2 \%$ spent more than $\$ 7500$. Among the $14.3 \%$ of users enrolled in highdeductible health plans, mean annual out-of-pocket spending was \$581 (median \$123), compared with \$291 (median \$90) among other users.

The top 10 drugs by out-of-pocket spending accounted for $84 \%$ of out-of-pocket spending on orphan drugs in the sample (Table 2).

\section{DISCUSSION}

Among commercially insured patients who filled orphan drug prescriptions, mean total and out-of-pocket spending on these drugs in 2014 was \$10,786 and \$333, respectively. Our results suggest that commercial insurance benefit design protects most patients from high orphan drug prices. However, this protection is not distributed equally. In 2014, out-of-pocket spending exceeded $\$ 500$ for 1 in 7 patients and exceeded $\$ 7500$ for 2 in 1000 patients.

Estimates exclude out-of-pocket spending for orphan drug utilization that was not reimbursed through pharmacy benefits (e.g., physician-administered drugs), and do not account for 
Table 1 Fills and Spending on Orphan Drug Prescriptions, MarketScan 2014

\begin{tabular}{|c|c|}
\hline \multicolumn{2}{|l|}{ Orphan drug prescription fills ${ }^{\mathrm{a}}$} \\
\hline Number of individuals in sample & $19,182,738$ \\
\hline Number of orphan drug prescriptions fills & 744,182 \\
\hline Number of patients filling $\geq 1$ orphan drug prescription in 2014 ("orphan drug users") & 200,207 \\
\hline Mean number of orphan drug prescription fills per orphan drug user & 3.7 \\
\hline \multicolumn{2}{|l|}{ Total spending on orphan drug prescription fills } \\
\hline Mean annual spending per orphan drug prescription fill (median, inter-quartile range) & $\$ 2902(\$ 1614, \$ 2623)$ \\
\hline Mean total annual spending per orphan drug user (median, inter-quartile range) & $\$ 10,786(\$ 727, \$ 11,091)$ \\
\hline \multicolumn{2}{|l|}{ Out-of-pocket spending on orphan drug prescription fills } \\
\hline Total annual co-payments on orphan drug prescription fills (\$ million) & $\$ 38.5$ \\
\hline Total annual deductible payments on orphan drug prescription fills (\$ million) & $\$ 14.9$ \\
\hline Total annual co-insurance payments on orphan drug prescription fills (\$ million) & $\$ 13.4$ \\
\hline Total annual out-of-pocket spending on orphan drug prescription fills ( $\$$ million) & $\$ 66.8$ \\
\hline Mean out-of-pocket spending per orphan drug prescription fill (median, inter-quartile range) & $\$ 90(\$ 40, \$ 50)$ \\
\hline Mean annual out-of-pocket spending per orphan drug user (median, inter-quartile range) & $\$ 333(\$ 96, \$ 244)$ \\
\hline \multicolumn{2}{|l|}{ Distribution of annual out-of-pocket spending per orphan drug user } \\
\hline \multicolumn{2}{|l|}{ Percent of orphan drug users with: } \\
\hline$\$ 0-\$ 100$ in annual out-of-pocket spending & $52.6 \%$ \\
\hline$\$ 101-\$ 250$ in annual out-of-pocket spending & $20.5 \%$ \\
\hline$\$ 251-\$ 500$ in annual out-of-pocket spending & $13.3 \%$ \\
\hline$\$ 501-\$ 1000$ in annual out-of-pocket spending & $7.1 \%$ \\
\hline$\$ 1001-\$ 1500$ in annual out-of-pocket spending & $2.5 \%$ \\
\hline$\$ 1501-\$ 2000$ in annual out-of-pocket spending & $1.0 \%$ \\
\hline$\$ 2001-\$ 2500$ in annual out-of-pocket spending & $0.7 \%$ \\
\hline$\$ 2501-\$ 5000$ in annual out-of-pocket spending & $2.0 \%$ \\
\hline$\$ 5001-\$ 7500$ in annual out-of-pocket spending & $0.4 \%$ \\
\hline$>\$ 7500$ in annual out-of-pocket spending & $0.2 \%$ \\
\hline
\end{tabular}

${ }^{a}$ To identify orphan drugs, we identified drugs in the FDA orphan database that (1) were approved to be marketed as an orphan drug by January 1 , 2014 (i.e., had at least one FDA-approved orphan indication by this date) and (2) maintained market exclusivity throughout 2014. We included six drugs that did not have an exclusivity end date listed in the database, but had marketing approval dates during or after 2010, implying market exclusivity until at least 2017 (Lumizyme, Elelyso, Gammaplex, Sylatron, Vpriv, and Xyntha). We excluded Wilate because orphan status was rescinded in 2012. For the resulting 121 unique drugs, we merged brand names with the 2015 Truven Redbook to generate a list of national drug codes (NDCs). In a few cases in which the Redbook did not contain NDCs for an orphan drug, we identified NDCs based on a search of the FDA Orange Book. For two drugs (coccidioidin SD skin test antigen and botulism antitoxin), we could not find any associated NDCs. These drugs were eliminated, leaving 119 orphan drugs in our study. Of these, 97 were filled at least once in 2014 by our sample

Table 2 Top 10 Orphan Drugs Accounting for the Most Out-of-pocket Spending, MarketScan 2014

\begin{tabular}{|c|c|c|c|c|c|}
\hline $\begin{array}{l}\text { Brand name } \\
\text { (generic name; manufacturer; orphan indications }{ }^{\mathbf{a}} \text { ) }\end{array}$ & $\begin{array}{l}\text { Total } \\
\text { fills }\end{array}$ & $\begin{array}{l}\text { Total } \\
\text { spending }\end{array}$ & $\begin{array}{l}\text { Total } \\
\text { spending } \\
\text { per fill }\end{array}$ & $\begin{array}{l}\text { Out-of- } \\
\text { pocket } \\
\text { spending }\end{array}$ & $\begin{array}{l}\text { Out-of-pocket } \\
\text { spending per } \\
\text { fill }\end{array}$ \\
\hline $\begin{array}{l}\text { Humira } \\
\text { (adalimumab; Abbvie; juvenile rheumatoid arthritis) }\end{array}$ & 253,372 & $\$ 994,723,784$ & $\$ 3926$ & $\$ 32,837,680$ & $\$ 130$ \\
\hline $\begin{array}{l}\text { Colcrys } \\
\text { (colchicine; AR Holding Company; familial Mediterranean fever) }\end{array}$ & 204,185 & $\$ 46,114,018$ & $\$ 226$ & $\$ 8,905,880$ & $\$ 44$ \\
\hline $\begin{array}{l}\text { Viread } \\
\text { (tenofovir; Gilead Sciences; pediatric HIV infection) }\end{array}$ & 33,249 & $\$ 41,060,656$ & $\$ 1235$ & $\$ 2,641,165$ & $\$ 79$ \\
\hline $\begin{array}{l}\text { Normix } \\
\text { (rifaximin; Salix; hepatic encephalopathy) }\end{array}$ & 28,985 & $\$ 35,551,145$ & $\$ 1227$ & $\$ 2,059,552$ & $\$ 71$ \\
\hline $\begin{array}{l}\text { Gleevec } \\
\text { (imatinib mesylate; Novartis; gastrointestinal stromal tumors and } \\
\text { acute lymphoblastic leukemia) }\end{array}$ & 14,779 & $\$ 163,321,123$ & $\$ 11,051$ & $\$ 1,865,557$ & $\$ 126$ \\
\hline $\begin{array}{l}\text { Durezol } \\
\text { (difluprednate; Alcon; anterior uveitis and panuveitis) }\end{array}$ & 43,239 & $\$ 5,656,205$ & $\$ 131$ & $\$ 1,782,241$ & $\$ 41$ \\
\hline $\begin{array}{l}\text { Ampyra } \\
\text { (dalfampridine; Acorda; multiple sclerosis) }\end{array}$ & 17,358 & $\$ 39,608,120$ & $\$ 2282$ & $\$ 1,751,424$ & $\$ 101$ \\
\hline $\begin{array}{l}\text { Revlimid } \\
\text { (lenalidomide; Celgene; mantle cell lymphoma) }\end{array}$ & 14,565 & $\$ 138,927,525$ & $\$ 9538$ & $\$ 1,662,057$ & $\$ 114$ \\
\hline $\begin{array}{l}\text { Gralise } \\
\text { (gabapentin; Depomed; post-herpetic neuralgia) }\end{array}$ & 24,199 & $\$ 9,020,026$ & $\$ 373$ & $\$ 1,369,261$ & $\$ 57$ \\
\hline $\begin{array}{l}\text { Sensipar } \\
\text { (cinacalcet; Amgen; hypercalcemia in primary hyperparathyroidism) }\end{array}$ & 19,485 & $\$ 21,728,071$ & $\$ 1115$ & $\$ 1,321,589$ & $\$ 68$ \\
\hline
\end{tabular}

${ }^{a}$ Drugs may have multiple orphan indications as well as non-orphan indications. Total and out-of-pocket spending in the table reflects both orphan and non-orphan use

${ }^{b}$ In the FDA orphan drug database, the brand name for rifaximin is listed as Normix. This drug is now marketed as Xifaxan

${ }^{c}$ Orphan status is assigned to a particular drug-manufacturer combination. Gabapentin manufactured by Depomed (brand name Gralise) is an orphan drug because it was granted an orphan indication for the treatment of post-herpetic neuralgia. Gabapentin manufactured by other companies does not have an orphan indication and therefore is not considered an orphan drug 
coupons or copay assistance programs. We could not determine whether patients had met deductibles or out-of-pocket limits at the time of prescription fills, or whether patients selfselected into plans with more generous pharmacy benefit coverage when offered a choice.

We did not assess recent trends in out-of-pocket spending since the mix of drugs with orphan status changes from yearto-year and since there was a substantial loss of data contributors to MarketScan after 2014. However, the number of orphan drugs, total spending on these drugs, and the use of deductibles and co-insurance in commercial insurance pharmacy benefits are each increasing. ${ }^{1,2}$ Consequently, out-ofpocket spending on orphan drugs may have risen since 2014, potentially exacerbating access barriers among patients undergoing treatment for rare diseases with few therapeutic alternatives. $^{6}$

Corresponding Author: Kao-Ping Chua, MD, PhD; Department of Pediatrics and Communicable Diseases, Child Health Evaluation and Research Center, University of Michigan Medical School, Ann Arbor, MI, USA (e-mail: chuak@med.umich.edu).

\section{Compliance with Ethical Standards:}

Disclosures: Dr. Conti served on the National Academy of Sciences, Engineering, and Medicine Committee "Ensuring Patient Access to
Affordable Drug Therapies." Dr. Conti reports funding from The Commonwealth Fund and the American Cancer Society for her work on this study.

Conflict of Interest: The authors declare that they do not have a conflict of interest.

\section{REFERENCES}

1. QuintilesIMS Institute. Orphan drugs in the United States: providing context for use and cost. 2017. http://www.iqvia.com/institute/reports/ orphan-drugs-in-the-united-states.

2. Kasier Family Foundation. Examining high prescription drug spending for people with employer sponsored health insurance. 2016. https://www. healthsystemtracker.org/brief/examining-high-prescription-drug-spending-for-people-with-employer-sponsored-health-insurance/. Accessed 15 April 2018.

3. Faden L, Huskamp, H. Medicare Part D Coverage and Reimbursement of Orphan Drugs. In: Field MJ, Boat TF, eds. Rare Disease and Orphan Products: Accelerating Research and Development. Washington, DC: National Academies Press; 2010.

4. Hansen LG, Chang $\mathbf{S}$. Health research data for the real world: the MarketScan databases. 2011. http://truvenhealth.com/portals/0/assets/PH_11238_0612_TEMP_MarketScan_WP_FINAL.pdf. Accessed 15 April 2018.

5. Food and Drug Administration. Orphan drug designations and approvals. 2017. https://www.accessdata.fda.gov/scripts/opdlisting/oopd/index. cfm. Accessed 15 April 2018.

6. Dusetzina SB, Winn AN, Abel GA, Huskamp HA, Keating NL. Cost sharing and adherence to tyrosine kinase inhibitors for patients with chronic myeloid leukemia. J Clin Oncol. 2014;32(4):306-311. 